\title{
Construction of the Evaluation Index System of Enterprise Tacit Knowledge
}

\author{
Liu Yang \\ College of Economics and Management \\ Dalian University \\ Dalian, 116622 ,China \\ 1_y_apple@163.com
}

\begin{abstract}
Evaluation of enterprise tacit knowledge is the foundation of enterprise tacit knowledge management, which can make the enterprise master the state of tacit knowledge at any time and can help enterprises clearly understand development direction of its own tacit knowledge. This paper determines the evaluation index of enterprise tacit knowledge based on the configuration and characteristics of enterprise tacit knowledge, then, in view of enterprise tacit knowledge evaluation characteristics, introduces the Fuzzy AHP (Analytical Hierarchy Process) to determine index weight, and constructs the evaluation index system of enterprise tacit knowledge containing all dimension indexes of enterprise tacit knowledge and their weights in order to realize effective evaluation to enterprise tacit knowledge.
\end{abstract}

Keywords- enterprise tacit knowledge;index system;the Fuzzy AHP; evaluation; index weight

\section{INTRODUCTION}

As an important means of strategic management, evaluation of enterprise tacit knowledge is the basis of the effective management of enterprises tacit knowledge, which can make the enterprise master the state of tacit knowledge at any time, help enterprises to verify its ability to achieve strategic goals, plan knowledge development and accumulation, indicate the direction for the cultivation of the core competitiveness $[1,2]$.

Because the tacit knowledge is hidden among individuals or organizations at all levels, academia has not yet developed theory and method of very directly evaluating the tacit knowledge at present[3,4]. So evaluation of enterprise tacit knowledge is actually the measurement to directly or indirectly related variables of enterprise tacit knowledge of measurement, the former conditions is reflected by the latter, and judgement can be got according to evaluation indexes .Based on the idea, this paper builds the evaluation index system of enterprise tacit knowledge according to the configuration and characteristics of enterprise tacit knowledge, introduces the Fuzzy AHP to determine index weight in view of enterprise tacit knowledge evaluation characteristics, and thus provides theoretical basis for realizing effective evaluation to enterprise tacit knowledge[5].

\section{SPECIFIC ASSESSMENT INDICATORS OF ENTERPRISES TACIT KNOWLEDGE}

This paper has carried on the comprehensive study to the domestic and foreign research literature about the tacit knowledge, and then combining with conclusion about the enterprise tacit knowledge structure exploration and empirical research, has always induced 28 specific evaluation indicators relating the enterprise tacit knowledge, which include three layers tacit knowledge ,that is, the individual, community and enterprise and cover six aspects of tacit knowledge, that is staff skills ,cognition of employee, corporate culture, organization coordination, tacit technology and external relationship. The evaluation index factors of enterprise tacit knowledge are shown in table. $1[6,7]$.

TABLE I . EVALUATION INDEX FACTORS OF ENTERPRISE TACIT KNOWLEDGE

\begin{tabular}{|c|c|}
\hline dimension & assessment index \\
\hline Staff skills & $\begin{array}{l}\text { operation skills of staff } \\
\text { administrators' experience } \\
\text { professional sills of technicians } \\
\text { marketing personnel skills }\end{array}$ \\
\hline $\begin{array}{l}\text { Cognition } \\
\text { of employee }\end{array}$ & $\begin{array}{l}\text { staff learning ability } \\
\text { self-management ability of employee } \\
\text { working attitude of employee } \\
\text { creativity of R\&D personnel } \\
\text { enterpriser insight }\end{array}$ \\
\hline $\begin{array}{l}\text { Corporate } \\
\text { culture }\end{array}$ & $\begin{array}{l}\text { core values } \\
\text { professional morality } \\
\text { creative spirit } \\
\text { atmosphere for studying } \\
\text { corporate vision } \\
\text { enterprise cohesion }\end{array}$ \\
\hline $\begin{array}{l}\text { Organization } \\
\text { coordination }\end{array}$ & $\begin{array}{l}\text { team tacit agreement } \\
\text { cooperation between Departments } \\
\text { project integration ability } \\
\text { superior-subordinate relationship } \\
\text { strategic control and harmonious }\end{array}$ \\
\hline $\begin{array}{l}\text { Tacit } \\
\text { technology }\end{array}$ & $\begin{array}{l}\text { Non-imitativeness of Core technology } \\
\text { flexibility of core technology } \\
\text { technical development ability } \\
\text { absorptive and extension of technology }\end{array}$ \\
\hline $\begin{array}{l}\text { External } \\
\text { relationship }\end{array}$ & $\begin{array}{l}\text { ability of external information acquisition } \\
\text { external communication } \\
\text { strategic partnership } \\
\text { market development }\end{array}$ \\
\hline
\end{tabular}




\section{THE CALCULATION METHOD OF INDEX WEIGHT}

When establishing comparison matrix, the judgment values given by the expert is usually not specific numerical points, but the fuzzy value, So this paper introduces the fuzzy analytic hierarchy process to determine the index weight. The fuzzy analytic hierarchy process Fuzzy analytic hierarchy process (FAHP) is the system decision-making method combining the advantages of fuzzy theory method and analytic hierarchy process (AHP) .The heart of the AHP method is to construct comparative judgment matrix by taking natural number and its reciprocal as degrees. Through pairwise comparison, judgment of indicators and computation, the weights are obtained. FAH $\mathrm{P}$ makes the paired comparison value of analytic hierarchy process blurred and constructs comparative judgment matrix by using fuzzy number as a degree. Compared with AHP, main advantages of FAHP are that it retains the uncertain fuzzy information and can better reflect fuzziness the subjective judgment. Existing research shows that the weight determined by FAHP is more reasonable and more scientific than the traditional AHP.The steps to determine index weight are used as follows:

\section{A. Language Variable Values of Fuzzy Numbers}

Language variable is the one using word in natural language as the value, rather than the variable using data as the value, for example, experts express the relative importance of tacit knowledge evaluation indicators by Language variable. Fuzzy AHP firstly need to express semantic value from the judgment matrix with fuzzy numbers. Here we choose the triangle fuzzy number as subordinate function of expert language variable, that is relative importance scale of the indicators is the triangular fuzzy number, for example fuzzy number $(a, b, c)$.

\section{B. To Construct the Fuzzy Judgment Matrix}

To construct the fuzzy judgment matrix is the key of the fuzzy AHP. The established fuzzy judgment matrix by determining the semantic variable fuzzy number is as follows:

$$
\tilde{F}^{p}=\left[\tilde{F}_{i j}\right]_{n \times n}
$$

In here, $\tilde{F}^{p}$ is fuzzy judgment matrix of the first $\mathrm{p}$ evaluation expert; $\tilde{F}_{i j}$ is compare value of importance about the first $\mathrm{i}$ indicator and the first $\mathrm{j}$ indicator.

$$
\begin{gathered}
\tilde{F}^{p}=1, \forall i=j ; \\
\tilde{F}_{j i}{ }^{p}=1 / \tilde{F}_{i j}{ }^{p}, \forall i, j=1,2, \cdots, n,
\end{gathered}
$$

in here $\mathrm{P}$ is the number of specialists of evaluating index weight.

\section{To Calculate Fuzzy Weight}

According to the fuzzy judgment matrix, applying Lambda - Max method proposed by buckley $[8,9]$, we calculate the fuzzy weighted values of different levels of fuzzy hierarchy analysis. The calculation steps and methods are as follows
To make $\alpha=1, F_{b}^{p}=\left[F_{i j b}^{p}\right]_{n \times n}$,a clear value judgment matrix of $\mathrm{t}$ the first $\mathrm{p}$ evaluation experts is calculated by $\alpha$-cut sets. By AHP calculating weight, the weight vector $W_{b}{ }^{p}$ is got ,in here

$$
W_{b}^{p}=\left[W_{i b}^{p}\right], i=1,2, \ldots n
$$

To make $\alpha=0$, a clear value judgment matrix of $\mathrm{t}$ the first $\mathrm{p}$ evaluation experts is calculated by $\alpha$-cut sets, that is $F_{a}^{p}=\left[F_{i j a}^{p}\right]_{n \times n}, F_{c}^{p}=\left[F_{i j c}^{p}\right]_{n \times n}$ respectively, By AHP calculating weight, the weight vector $W_{a}^{p}$ and $W_{c}^{p}$ are got.

In order to ensure that weight value of calculation is a fuzzy number, we need to get adjust coefficient through the following formula:

$$
\begin{gathered}
K_{a}^{p}=\min \left\{W_{i b}^{p} / W_{i a}^{p} 1 \leq i \leq n\right\} \\
K_{c}^{p}=\max \left\{W_{i b}^{p} / W_{i c}^{p} 1 \leq i \leq n\right\}
\end{gathered}
$$

Then calculating thelower limit and upper limit for the weight of every level :

$$
\begin{gathered}
W_{i a}^{p}=K_{a}^{p} W_{i a}^{p}, \\
W_{i c}^{p}=K_{a}^{p} W_{i c}^{p}
\end{gathered}
$$

By them I fuzzy weighted vector of the first $p$ evaluation expert can be got:

$$
\tilde{W}^{p}=\left[\tilde{W}_{i}^{p}\right]=\left[\left(W_{i a}^{p}, W_{i b}^{p}, W_{i c}^{p}\right)\right] ;
$$

Finally, fuzzy weighted value by integrating $\mathrm{p}$ experts based on average method is as follows:

$$
\tilde{\bar{W}}_{i}=1 / p\left(\tilde{W}_{i}^{1} \oplus \tilde{W}_{i}^{2} \oplus \wedge \oplus \tilde{W}_{i}^{p}\right)
$$

\section{THE DETERMINATION OF INDEX WEIGHT VALUE}

As mentioned above, the fuzzy AHP can reduce the subjective factors of evaluators and improve the rationality of the weight distribution. In here, We use this method to calculate index weight.

\section{A. To Determine e Fuzzy Number of Semantic Variable}

Table II. The relation between semantics variable and fuzzy number

\begin{tabular}{llc}
\hline NO. & Weight language & Triangle fuzzy number \\
\hline 1 & Equal importance & $(1,1,1)$ \\
2 & A little important & $(1,3,5)$ \\
3 & A more important & $(3,5,7)$ \\
4 & very important & $(5,7,9)$ \\
5 & Absolutely important & $(7,9,9)$ \\
\hline
\end{tabular}


Given the relationship between the values of semantic variables and the triangular fuzzy number (table2), we invited four experts evaluate the relative importance of tacit knowledge evaluation indexes. Experts do pairwise comparison among six assessment dimensions and among different indexes within each dimension, and give the semantic value. And then according to corresponding relations of the table2, the semantic values of experts are converted into triangular fuzzy numbers[10].

\section{B. The Fuzzy Weighted Value of Each Dimension}

Comparison matrix is constructed according to the importance evaluation results of the four experts to six dimension measurement, and fuzzy judgment matrix that is evaluation results of each expert are established respectively.

$$
\begin{gathered}
\tilde{F}_{1}=\left[\begin{array}{cccccc}
(1,1,1) & (1,1 / 3,1 / 5) & (1,3,5) & (1 / 3,1 / 5,1 / 7) & (1,3,5) & (1,1 / 3,1 / 5) \\
(1,3,5) & (1,1,1) & (1,3,5) & (1 / 3,1 / 5,1 / 7) & (1,1 / 3,1 / 5) & (1,3,5) \\
(1,1 / 3,1 / 5) & (1,1 / 3,1 / 5) & (1,1,1) & (1,3,5) & (3,5,7) & (1,1 / 3,1 / 5) \\
(3,5,7) & (3,5,7) & (1,1 / 3,1 / 5) & (1,1,1) & (1,1 / 3,1 / 5) & (5,7,9) \\
(1,1 / 3,1 / 5) & (1,3,5) & (1 / 3,1 / 5,1 / 7) & (1,3,5) & (1,1,1) & (1 / 5,1 / 7,1 / 9) \\
(1,3,5) & (1,1 / 3,1 / 5) & (1,3,5) & (1 / 5,1 / 7,1 / 9) & (5,7,9) & (1,1,1)
\end{array}\right] \\
\tilde{F}_{2}=\left[\begin{array}{ccccccc}
(1,1,1) & (1,1 / 3,1 / 5) & (1,1 / 3,1 / 5) & (3,5,7) & (1 / 3,1 / 5,1 / 7) & (1,1 / 3,1 / 5) \\
(1,3,5) & (1,1,1) & (1,1 / 3,1 / 5) & (1 / 3,1 / 5,1 / 7) & (3,5,7) & (1,1 / 3,1 / 5) \\
(1,3,5) & (1,3,5) & (1,1,1) & (1,1 / 3,1 / 5) & (1,1 / 3,1 / 5) & (1,3,5) \\
(1 / 3,1 / 5,1 / 7) & (3,5,7) & (1,3,5) & (1,1,1) & (1,1 / 3,1 / 5) & (3,5,7) \\
(3,5,7) & (1 / 3,1 / 5,1 / 7) & (1,3,5) & (1,3,5) & (1,1,1) & (1,1 / 3,1 / 5) \\
(1,3,5) & (1,3,5) & (1,1 / 3,1 / 5) & (1 / 3,1 / 5,1 / 7) & (1,3,5) & (1,1,1)
\end{array}\right] \\
\tilde{F}_{3}=\left[\begin{array}{cccccc} 
& & & \\
(1,1,1) & (1,1 / 3,1 / 5) & (1,3,5) & (3,5,7) & (1,1 / 3,1 / 5) & (1,1 / 3,1 / 5) \\
(1,3,5) & (1,1,1) & (1 / 3,1 / 5,1 / 7) & (5,7,9) & (1 / 3,1 / 5,1 / 7) & (1,3,5) \\
(1,1 / 3,1 / 5) & (3,5,7) & (1,1,1) & (1 / 5,1 / 7,1 / 9) & (1 / 5,1 / 7,1 / 9) & (1,1 / 3,1 / 5) \\
(1 / 3,1 / 5,1 / 7) & (1 / 5,1 / 7,1 / 9) & (5,7,9) & (1,1,1) & (1 / 5,1 / 7,1 / 9) & (1,3,5) \\
(1,3,5) & (3,5,7) & (5,7,9) & (5,7,9) & (1,1,1) & (1,1 / 3,1 / 5) \\
(1,3,5) & (1,1 / 3,1 / 5) & (1,3,5) & (1,1 / 3,1 / 5) & (1,3,5) & (1,1,1)
\end{array}\right] \\
\tilde{F}_{4}=\left[\begin{array}{ccccccc}
(1,1,1) & (1,3,5) & (1,3,5) & (1,1 / 3,1 / 5) & (1,1 / 3,1 / 5) & (1 / 5,1 / 7,1 / 9) \\
(1,1 / 3,1 / 5) & (1,1,1) & (1,1 / 3,1 / 5) & (1 / 7,1 / 9,1 / 9) & (1,1 / 3,1 / 5) & (5,7,9) \\
(1,1 / 3,1 / 5) & (1,3,5) & (1,1,1) & (5,7,9) & (1,3,5) & (1,1 / 3,1 / 5) \\
(1,3,5) & (7,9,9) & (1 / 5,1 / 7,1 / 9) & (1,1,1) & (1 / 5,1 / 7,1 / 9) & (1,3,5) \\
(1,3,5) & (1,3,5) & (1,1 / 3,1 / 5) & (5,7,9) & (1,1,1) & (1,1 / 3,1 / 5) \\
(5,7,9) & (1 / 5,1 / 7,1 / 9) & (1,3,5) & (1,1 / 3,1 / 5) & (1,3,5) & (1,1,1)
\end{array}\right]
\end{gathered}
$$

Based on the formula (2), (3), (4), fuzzy weighted value of each assessment dimensions is obtained by Matlab7.0 programming arithmetic, that is:

$$
\begin{aligned}
& \tilde{W}_{1}=(0.10,0.11,0.12), \quad \tilde{W}_{2}=(0.11,0.16,0.17), \\
& \tilde{W}_{3}=(0.11,0.15,0.17), \quad \tilde{W}_{4}=(0.16,0.21,0.23), \\
& \tilde{W}_{5}=(0.14,0.20,0.22), \quad \tilde{W}_{6}=(0.11,0.17,0.21)
\end{aligned}
$$

\section{The Fuzzy Weighted Values of Each Dimension Evaluation Indexes}

Calculation steps of index weight are the same as the above process, fuzzy weighted values of various assessment indexes in staff skills dimension are calculated by the fuzzy AHP, which are respectively:

$$
\begin{aligned}
& \tilde{W}_{11}=(0.22,0.26,0.26), \tilde{W}_{12}=(0.20,0.22,0.27), \\
& \tilde{W}_{13}=(0.20,0.24,0.26), \tilde{W}_{14}=(0.24,0.28,0.30)
\end{aligned}
$$


Fuzzy weighted values of various assessment indexes in cognition of employee dimension are respectively:

$$
\begin{aligned}
& \tilde{W}_{21}=(0.14,0.16,0.19), \tilde{W}_{22}=(0.19,0.24,0.25) \\
& \tilde{W}_{23}=(0.20,0.26 .0 .22), \tilde{W}_{24}=(0.18,0.20,0.20) \\
& \tilde{W}_{25}=(0.14,0.14,0.17)
\end{aligned}
$$

Fuzzy weighted values of various assessment indexes in corporate culture dimension are respectively:

$$
\begin{aligned}
& \tilde{W}_{31}=(0.15,0.16,0.17), \tilde{W}_{32}=(0.17,0.22 .0 .18), \\
& \tilde{W}_{33}=(0.12,0.16 .0 .18), \tilde{W}_{34}=(0.11,0.14,0.16) \\
& \tilde{W}_{35}=(0.17,0.18,0.21), \tilde{W}_{36}=(0.12,0.14,0.18)
\end{aligned}
$$

Fuzzy weighted values of various assessment indexes in organization coordination dimension are respectively:

$$
\begin{aligned}
& \tilde{W}_{41}=(0.21,0.21,0.22), \tilde{W}_{42}=(0.17,0.18,0.19) \\
& \tilde{W}_{43}=(0.20,0.26,0.23), \tilde{W}_{44}=(0.19,0.20,0.21) \\
& \tilde{W}_{45}=(0.13,0.15,0.22)
\end{aligned}
$$

Fuzzy weighted values of various assessment indexes in tacit technology dimension are respectively:

$$
\begin{aligned}
& \tilde{W}_{51}=(0.20,0.24,0.27), \tilde{W}_{52}=(0.23,0.27,0.28), \\
& \tilde{W}_{53}=(0.24,0.28,0.30), \tilde{W}_{54}=(0.20,0.21,0.25)
\end{aligned}
$$

Fuzzy weighted values of various assessment indexes in external relationship dimension are respectively:

$$
\begin{aligned}
& \tilde{W}_{61}=(0.20,0.25,0.27), \tilde{W}_{62}=(0.24,0.28,0.28), \\
& \tilde{W}_{63}=(0.23,0.25,0.28), \tilde{W}_{64}=(0.21,0.22,0.26)
\end{aligned}
$$

\section{CONCLUSIONS}

Although the tacit knowledge has the very high uncertainty, the enterprise tacit knowledge can be measure and only measurement is more complex. Evaluation of enterprises tacit knowledge is not the direct evaluation of tacit knowledge, but rather is realized through the measures to tacit knowledge carrier. So enterprises tacit knowledge evaluation is a kind of indirect evaluation theory and methods. According to the characteristics and structure of the enterprise tacit knowledge, this paper constructs evaluation index system covering six dimensions and 28 elements, and then introduces the calculating process of tacit knowledge weights in the detail to provides a theoretical basis for evaluation and implementation of enterprise tacit knowledge.

\section{ACKNOWLEDGMENT}

The research work was supported by Humanities and Social Science Foundation of Education Department of Liaoning province under Grant No. W2013276. and Social Science Foundation of Social Science Association of Liaoning Province under Grant No. 20131slktzjjx-10.

\section{REFERENCES}

[1] Anna T.Cianciolo,Elena L. Grigorenko,Linda Jarvin, "Practical interlligence and tacit knowledge: adancements in the measurement of developing expertise,"Learning and Individual Differences, vol.16, 2006 ,pp.235-253.

[2] Foss N J., "Knowledge-based Approaches to the theory of the firm: some critical comments,"Organization Science, vol.3, 2004, pp. 470-476.

[3] Tsai W., Knowledge transfer intra-organizational networks: effects of network position and absorptive capacity on business unit innovation and performance . Academy of Management Journal, 44 (5), 2007, pp.36-44.

[4] Scott J Lochner.,"Risk-minimization strategies in licensing intellectual property from entities that are,or might become,financially troubled,'Intellectual Property \$ Technology Law Journal,vol.14, 2002 ,pp.7-11.

[5] Daniel Gervais, "Traditional Knowledge \& Intellectual Property: A Trips-Compatible Approach,'Detroit College of Law Michigan State Law Review, Spring 2005, pp.137-166.

[6] Neslihan Aydogana, Thomas P L., " Spatial Proximity and Complementarities in the Trading of Tacit Knowledge",International Journal of Industrial Organization, vol.22,2004, pp1115-1135.

[7] Foss N J. , "Knowledge-based Approaches to the Theory of the Firm: Some Critical Comments,'Organization Science, vol.3,2004,pp.470-476.

[8] Buckley J, Feuring T,Hayashi Y., "Fuzzy hierarchical analysis revisited,"European Journal of Operational Research, vol.129, 2001, pp.48-64.

[9] Custora R, Buckley J., "Fuzzy Hierarchical analysis: the lambdamax metho," Fuzzy sets and systems, vol.120, 2001, pp.181-195.

[10] Zimmerman H J., Fuzzy Set Theory and Its Application. Boston: Kluwer Academic Publishers, 2002. 